\title{
Sputum Eicosanoid Profiling in Exacerbations of Chronic Obstructive Pulmonary Disease
}

\author{
Orsolya Drozdovszky ${ }^{a}$ Imre Barta ${ }^{a}$ Balazs Antus ${ }^{a}$ b \\ Departments of a Pathophysiology, and ${ }^{b}$ Pulmonology, National Koranyi Institute of TB and Pulmonology, \\ Budapest, Hungary
}

\section{Key Words}

Biomarker · Inflammation · Oxidative stress · Prostaglandin $\mathrm{E}_{2} \cdot$ Repeatability $\cdot$ Treatment

\begin{abstract}
Background: Eicosanoids are small lipid molecules with diverse biological functions in the airways. Objectives: The aim of this study was to investigate changes in leukotriene $\mathrm{B}_{4}\left(\mathrm{LTB}_{4}\right)$, 8-isoprostane, prostaglandin $\mathrm{E}_{2}\left(\mathrm{PGE}_{2}\right)$ and cysteinyl-leukotriene (cys-LT) levels in the sputum of patients with chronic obstructive pulmonary disease (COPD) at the onset of a severe exacerbation and during the course of recovery. Methods: Thirty-seven ex-smoker COPD patients suffering an episode of acute exacerbation were enrolled. Samples were taken (i) on hospital admission and (ii) after regular treatment. Twenty-five stable ex-smoker COPD patients served as controls. Eicosanoids were determined by enzyme immunoassay. Results: Sputum PGE 2 [39.8 (13.3-103.3) vs. 5.05 (2.3-12.1) pg/ml, p < 0.001], 8-isoprostane [89.5 (36.9$184.7)$ vs. $29.7(13.8-68.8) \mathrm{pg} / \mathrm{ml}, \mathrm{p}<0.01]$ and $\mathrm{LTB}_{4}[587.7$ (252.9-774.8) vs. 276.1 (105.4-594.7) pg/ml, p < 0.05] levels were increased in patients with exacerbation compared to stable subjects. After treatment only $\mathrm{PGE}_{2}$ levels decreased significantly [at discharge: 19.6 (4.6-52.5) pg/ml, p < 0.01], the levels of other eicosanoids remained elevated ( $p=N S$ ). Sputum cys-LT levels were similar in stable patients and in those with exacerbation and treatment did not influence
\end{abstract}

cys-LTs either. There was a significant correlation between $\mathrm{PGE}_{2}$ and sputum neutrophil and lymphocyte cell counts in patients with exacerbation. Conclusions: Our results suggest that 8-isoprostane, $\mathrm{LTB}_{4}$ and $\mathrm{PGE}_{2}$ but not cys-LTs may be involved in exacerbation-associated inflammatory processes in the airways of patients with COPD. Validation of $\mathrm{PGE}_{2}$ for use as a biomarker of recovery from an exacerbation requires further studies.

(c) 2014 S. Karger AG, Basel

\section{Introduction}

Acute exacerbations of chronic obstructive pulmonary disease (COPD) are associated with increased inflammation and mediator release into the airways [1]. Among mediators involved in the development of exacerbations, arachidonic acid metabolites such as leukotrienes (LTs) and prostaglandins (PGs) may play an important role [2].

Several lines of evidence indicate that $\mathrm{LTB}_{4}$ acts as a potent neutrophil chemoattractant during exacerbations $[3,4]$. In asthma it has been extensively documented that cysteinyl-LTs (cys-LTs) including $\mathrm{LTC}_{4}, \mathrm{LTD}_{4}$ and $\mathrm{LTE}_{4}$ induce bronchoconstriction, increase mucus production and edema and promote airway remodeling [5] while $\mathrm{PGE}_{2}$ is an airway smooth muscle relaxant and is likely to have bronchoprotective and anti-inflammatory actions [6]. In COPD the role of these mediators is less clear.

\section{KARGER}

E-Mail karger@karger.com

www.karger.com/res
(C) 2014 S. Karger AG, Basel

0025-7931/14/0875-0408\$39.50/0 
Fig. 1. Flow chart showing the study profile in patients with exacerbations of COPD.

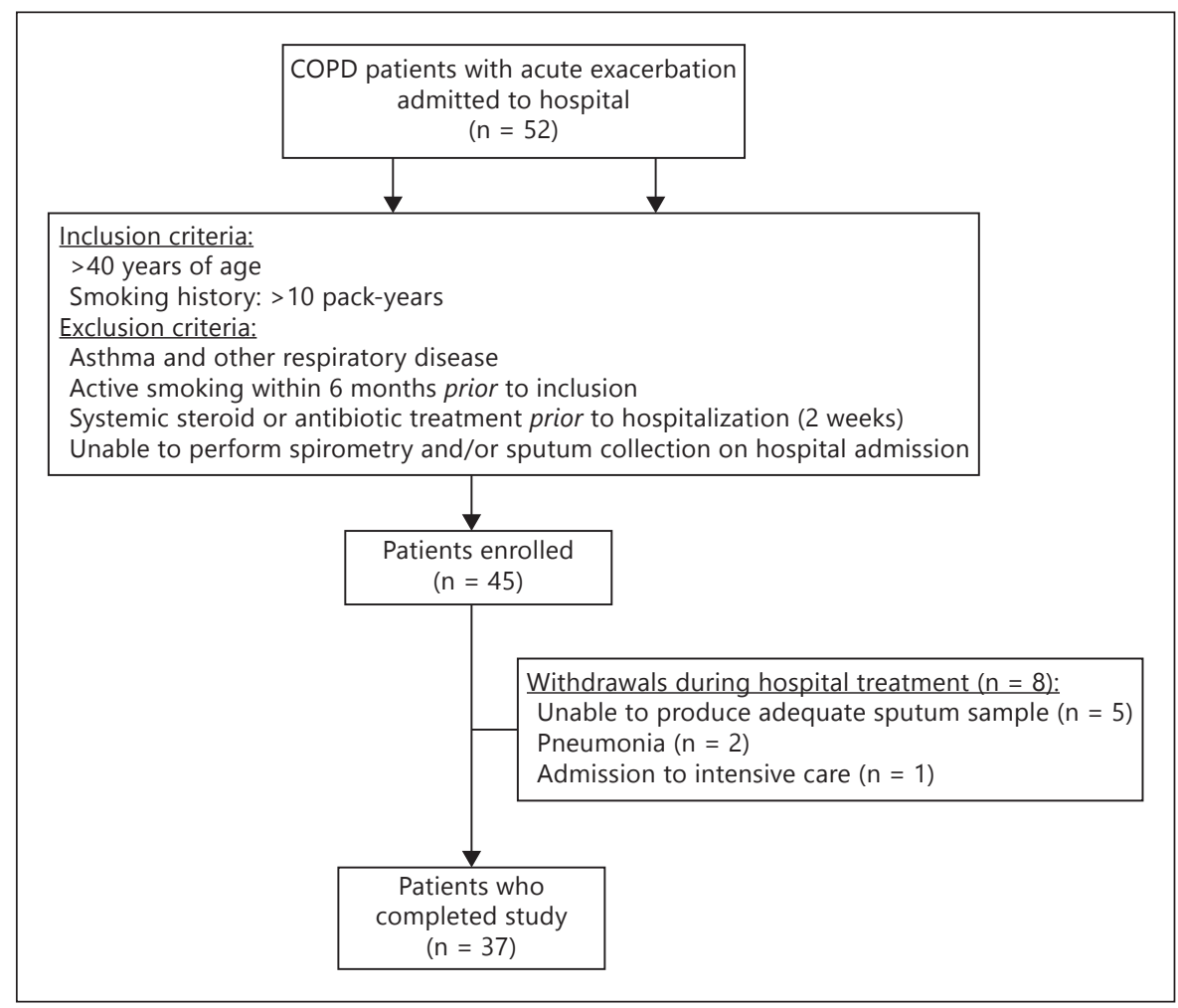

Montuschi et al. [7] reported an increased $\mathrm{PGE}_{2}$ concentration in exhaled breath condensate (EBC) of stable COPD patients and argued that, like in asthma, this might represent a protective mechanism for counteracting airway inflammation. However, $\mathrm{PGE}_{2}$ has also been implicated as an important mediator of cigarette smoke-induced neutrophil infiltration of the airways, indicating that $\mathrm{PGE}_{2}$ may have diverse and even opposing effects in respiratory diseases [8]. Moreover, an increase in cys-LTs in EBC [9] and a prominent cys-LT1 receptor expression [10] have also been recently demonstrated during the course of an exacerbation.

Isoprostanes represent a unique group of arachidonic acid derivatives, since they are produced nonenzymatically from arachidonic acid during the peroxidation of membrane lipids, and in addition to having relevant biological activities, may also be potentially useful biomarkers of oxidative stress [11]. In COPD exacerbations raised 8-isoprostane levels in EBC indicate augmented oxidative stress $[9,12,13]$.

Until recently, most studies had used EBC as a type of respiratory sample to profile eicosanoids in COPD exacerbations $[9,12,13]$. However, measurement of putative mediators in EBC usually have poor reproducibility [14, 15]. Moreover, biomarkers may be affected by the sam- pling procedure itself, as acknowledged in the European Respiratory Society Task Force Report [16].

Assessment of eicosanoids in the sputum supernatant is a more reliable approach to study the underlying pathophysiology and to identify pulmonary biomarkers of potential clinical utility in the management of the disease [17]. Nevertheless, major eicosanoid products in the sputum have not yet been simultaneously investigated in COPD exacerbations and in convalescence. Therefore, in this study, levels of $\mathrm{LTB}_{4}$, cys-LTs, $\mathrm{PGE}_{2}$ and 8-isoprostane in sputum were assessed in patients with COPD exacerbation at onset and after treatment.

\section{Materials and Methods}

\section{Study Subjects}

COPD patients with an acute exacerbation of the disease were recruited for the study between January 2012 and December 2012. Inclusion and exclusion criteria are summarized in figure 1. COPD exacerbation was defined as increased dyspnea, cough or sputum expectoration that led the subject to seek medical attention, as specified in international guidelines [18].

For comparison 25 clinically stable, ex-smoker COPD patients were additionally enrolled in the study (table 1). All patients were $>40$ years of age and had a smoking history of $>10$ pack-years and documented airway obstruction with forced expiratory volume in 
Table 1. Demographic and clinical characteristics of study subjects

\begin{tabular}{|c|c|c|c|}
\hline & \multirow{2}{*}{$\begin{array}{l}\text { Stable } \\
\text { COPD }\end{array}$} & \multicolumn{2}{|c|}{ COPD exacerbation } \\
\hline & & $\begin{array}{l}\text { on } \\
\text { admission }\end{array}$ & $\begin{array}{l}\text { after } \\
\text { treatment }\end{array}$ \\
\hline Subjects, n & 25 & \multicolumn{2}{|c|}{37} \\
\hline Sex, male/female, $\mathrm{n}$ & $15 / 10$ & \multicolumn{2}{|c|}{$22 / 15$} \\
\hline Age, years & $62.1 \pm 1.6$ & \multicolumn{2}{|c|}{$64.6 \pm 2.2$} \\
\hline Smoking, pack-years & $48.8 \pm 4.8$ & \multicolumn{2}{|c|}{$45.8 \pm 4.1$} \\
\hline \multicolumn{4}{|l|}{ GOLD stages, $\mathrm{n}$} \\
\hline I & $5(20 \%)$ & \multicolumn{2}{|c|}{$5(13 \%)$} \\
\hline II & $12(48 \%)$ & \multicolumn{2}{|c|}{$14(38 \%)$} \\
\hline III & $8(32 \%)$ & \multicolumn{2}{|c|}{$11(30 \%)$} \\
\hline IV & - & \multicolumn{2}{|c|}{$7(19 \%)$} \\
\hline \multicolumn{4}{|l|}{ Pulmonary function } \\
\hline FVC, liters & $3.55 \pm 0.21$ & $1.93 \pm 0.13^{\S}$ & $2.23 \pm 0.17^{\#}$ \\
\hline FVC, $\%$ predicted & $84.7 \pm 3.0$ & $65.4 \pm 3.4^{\S}$ & $76.5 \pm 4.0$ \\
\hline $\mathrm{FEV}_{1}$, liters & $2.91 \pm 0.11$ & $0.92 \pm 0.08^{\S}$ & $1.14 \pm 0.10^{\$}$ \\
\hline $\mathrm{FEV}_{1}, \%$ predicted & $63.4 \pm 4.5$ & $40.2 \pm 2.7^{\S}$ & $49.6 \pm 3.2^{\$}$ \\
\hline $\mathrm{FEV}_{1} / \mathrm{FVC}, \%$ & $50.8 \pm 2.1$ & $48.2 \pm 3.3$ & $53.7 \pm 2.5^{*}$ \\
\hline \multicolumn{4}{|l|}{ Blood gases } \\
\hline $\mathrm{PaCO}_{2}, \mathrm{kPa}$ & $5.14 \pm 0.11$ & $5.54 \pm 0.13$ & $5.80 \pm 0.14$ \\
\hline $\mathrm{PaO}_{2}, \mathrm{kPa}$ & $8.40 \pm 0.21$ & $6.81 \pm 0.20^{\S}$ & $7.16 \pm 0.15^{*}$ \\
\hline FENO, ppb & $\begin{array}{l}8.6 \\
(5.6-9.9)\end{array}$ & $\begin{array}{l}13.1 \\
(8.4-26.5)\end{array}$ & $\begin{array}{l}10.7 \\
(6.9-17.3)^{*}\end{array}$ \\
\hline
\end{tabular}

Data are presented as mean \pm SEM unless stated otherwise. $\mathrm{FVC}=$ Forced vital capacity; FENO = fractional exhaled nitric oxide (median, interquartile ranges); $\mathrm{ppb}=$ parts per billion; $\mathrm{PaCO}_{2}=$ arterial carbon dioxide tension; $\mathrm{PaO}_{2}=$ arterial oxygen tension.

${ }^{*} \mathrm{p}<0.05,{ }^{\#} \mathrm{p}<0.01$ or $^{\$} \mathrm{p}<0.001$ vs. admission, ${ }^{\S} \mathrm{p}<0.001$ vs. stable COPD.

$1 \mathrm{~s}\left(\mathrm{FEV}_{1}\right)<80 \%$ of predicted and postbronchodilator $\mathrm{FEV}_{1} /$ forced vital capacity $<0.7$. The research protocol was approved by the local Ethics Committee and all subjects gave written informed consent to participation in the study.

\section{Study Design}

In patients with exacerbation, spontaneously expectorated sputum was collected and levels of fractional exhaled nitric oxide, blood gases and lung function parameters were measured on hospital admission and on the day of discharge. In stable COPD patients induced sputum samples were collected during routine clinical visits. Lung function, blood gas parameters and fractional exhaled nitric oxide were determined, as previously described [19].

\section{Sputum Induction and Processing}

In stable COPD sputum was induced by the inhalation of a hypertonic saline solution ( $4 \%$ sodium chloride) delivered by an ultrasonic nebulizer (Ultra-Neb 2000, DeVilbiss Healthcare Ltd., Tipton, UK) with an output set at $1 \mathrm{ml} / \mathrm{min}$.

Spontaneous and induced sputum samples were processed similarly within $120 \mathrm{~min}$ from collection, as previously described [20]. At least 400 inflammatory cells were counted for each cytospin slide. The inflammatory cells in sputum were shown as a percentage of total nonsquamous cells (online suppl. table 1; for all online suppl. material, see www.karger.com/ doi/10.1159/000358099).

\section{Enzyme Immunoassays}

$\mathrm{LTB}_{4}, 8$-isoprostane, cys-LTs and a stable derivative of $\mathrm{PGE}_{2}$ were determined in sputum supernatants by enzyme immunoassays (EIA, Cayman Chemical, Ann Arbor, Mich., USA) according to the manufacturer's protocol, with the modification that dithiothreitol of the same concentration as in the sputum supernatant $(0.04 \%)$ was added to the standards in agreement with other studies [21]. The concentrations of eicosanoids were corrected for dilutions. The detection limits for $\mathrm{LTB}_{4}, 8$-isoprostane, cys-LTs and $\mathrm{PGE}_{2}$ in dithiothreitol-treated sputum supernatants were $18,4,28$ and $2 \mathrm{pg} / \mathrm{ml}$, respectively.

The repeatability of EIA measurements in the sputum was determined in a pilot study. Sputum samples collected from a subset of COPD patients $(n=6)$ were divided into two aliquots, which were analyzed separately (online suppl. table 2 ).

\section{Comparison of Eicosanoid Levels between Induced and}

Spontaneous Sputum

To compare eicosanoid levels in induced and spontaneous sputum, a subgroup of stable COPD patients $(n=10)$ capable of expectorating sputum spontaneously was selected. From these subjects both induced and spontaneous sputum samples were collected.

\section{Statistical Analysis}

Data are presented as mean \pm SEM or median with interquartile ranges when appropriate. Eicosanoid levels between stable and exacerbation patients were analyzed by the Mann-Whitney test. Paired Student's t test (parametric data) and the Wilcoxon signed rank test (nonparametric data) were used to compare variables measured on hospital admission and discharge. Correlation coefficients were calculated by Spearman's method. The repeatability of the EIA measurements was estimated by the coefficient of variation and the limits of agreement (Bland-Altman test). Power calculation was performed with $\alpha=0.05$ and 0.87 effect size. Calculations were performed by GraphPad Prism 4.0 (GraphPad Software Inc., San Diego, Calif., USA) and G*Power 3.1.1 (G*Power Software Inc., Kiel, Germany) software packages. A p value $<0.05$ was considered significant.

\section{Results}

Fifty-two COPD patients with exacerbation were screened, 45 fulfilled inclusion criteria and agreed to participate (fig. 1). During hospital treatment 8 patients were withdrawn. Demographic and clinical data of the 37 patients who completed the study are presented in table 1.

\section{Clinical Variables during Treatment of Exacerbations}

Exacerbations were treated with systemic glucocorticoids and bronchodilators (anticholinergics and/or $\beta_{2^{-}}$ agonists) in all cases. Antibiotics were given to $25 \mathrm{COPD}$ 
Table 2. Lipid mediator concentrations in induced and spontaneous sputum samples

\begin{tabular}{llcccc}
\hline Mediators, pg/ml & \multicolumn{2}{l}{ Sputum } & & \multirow{2}{*}{ CV, \% } & Limits of agreement \\
\cline { 2 - 5 } & spontaneous & induced & p value & & \\
\hline 8-Isoprostane & $183.0(4.1-1,233)$ & $195.7(3.4-1,299)$ & 0.937 & 18.9 & -179.1 and 127.2 \\
cys-LTs & $446.5(50.9-1,563)$ & $399.2(151.3-1,563)$ & 0.902 & 22.0 & -204.9 and 281.7 \\
PGE $_{2}$ & $28.7(6.6-80.6)$ & $22.4(2.2-81.4)$ & 0.605 & 21.8 & -13.2 and 22.1 \\
LTB $_{4}$ & $973.5(418.9-1,654)$ & $907.1(346.2-1,500)$ & 0.798 & 14.8 & -245.0 and 383.1 \\
\hline
\end{tabular}

Data are presented as median (interquartile ranges) unless stated otherwise. $\mathrm{CV}=\mathrm{Coefficient}$ of variation.

a Determined by the Bland-Altman test.

patients. The mean length of hospitalization was $12.0 \pm$ 2.9 days.

Lung function variables and $\mathrm{PaO}_{2}$ increased (table 1), while sputum total cell counts and the number of neutrophils decreased during the course of treatment (online suppl. table 1). By contrast, inflammatory cell type ratios were not changed.

\section{Comparison of Eicosanoid Levels between Induced and Spontaneous Sputum}

Eicosanoid levels obtained in spontaneous and induced sputum samples are given in table 2. Mediator levels in the two types of samples were similar.

\section{8-Isoprostane}

Apart from 1 patient in the stable COPD group, 8-isoprostane levels were above the detection limit in all subjects. Concentrations were significantly higher in patients with exacerbations compared to stable subjects [89.5 (36.9-184.7) vs. 29.7 (13.8-68.8) pg/ml, p < 0.01; fig. $2 \mathrm{a}]$, and remained elevated after treatment of exacerbation [84.1 (34.1-185.3) pg/ml].

\section{Cysteinyl-Leukotrienes}

Cys-LTs were detectable in all samples. Levels were slightly higher in patients with exacerbations, however, differences did not reach statistical significance [211.9 (128.6-827.1) vs. 469.9 (169.2-906.8) pg/ml, p = NS; fig. 2b]. Treatment had no effect on cys-LT concentrations [324.2 (114.3-698.1) pg/ml, p = NS].

\section{Prostaglandin $E_{2}$}

In the stable COPD group, $\mathrm{PGE}_{2}$ levels were detectable only in 13 patients. Among patients with exacerbation $\mathrm{PGE}_{2}$ was detectable in all cases. $\mathrm{PGE}_{2}$ concentrations were significantly higher in patients with exacerbation than in stable subjects [39.8 (13.3-103.3) vs. 5.05 (2.3-
12.1) $\mathrm{pg} / \mathrm{ml}, \mathrm{p}<0.001$; fig. $2 \mathrm{c}$ ]. Levels significantly decreased along with treatment $[19.6(4.6-52.5) \mathrm{pg} / \mathrm{ml}, \mathrm{p}<$ $0.01]$.

\section{Leukotriene $B_{4}$}

Among stable COPD patients $\mathrm{LTB}_{4}$ was detectable in all samples. Levels were increased in patients with exacerbation compared to stable subjects [587.7 (252.9-774.8) vs. 276.1 (105.4-594.7) pg/ml, p < 0.05; fig. 2d]. Treatment had no effect on $\mathrm{LTB}_{4}$ concentrations [661.5 (182.6758.1) $\mathrm{pg} / \mathrm{ml}, \mathrm{p}=\mathrm{NS}$ ] by the time of discharge. The power of the study to detect a standardized difference in 8-isoprostane, cys-LT, $\mathrm{PGE}_{2}$ and $\mathrm{LTB}_{4}$ between stable patients and those with exacerbation was $89,90,83$ and $89 \%$, respectively.

\section{Correlations}

Major correlation data are summarized in table 3 . Briefly, in stable patients significant correlations were observed between the number of neutrophils and 8-isoprostane or $\mathrm{LTB}_{4}$ concentrations in the sputum. Moreover, lymphocyte cell counts showed an association with 8-isoprostane and cys-LT levels.

In patients with exacerbations significant correlations were observed between sputum $\mathrm{PGE}_{2}$ levels and neutrophil or lymphocyte cell counts. Similarly, $\mathrm{LTB}_{4}$ and cysLT levels presented an association with the number of neutrophils. Other sputum cell types, spirometric and other clinical variables showed no correlations with lipid mediator levels (data not shown).

\section{Discussion}

In this study we investigated the sputum eicosanoid profile of COPD patients hospitalized with an acute exacerbation. The most striking finding of the study was that 

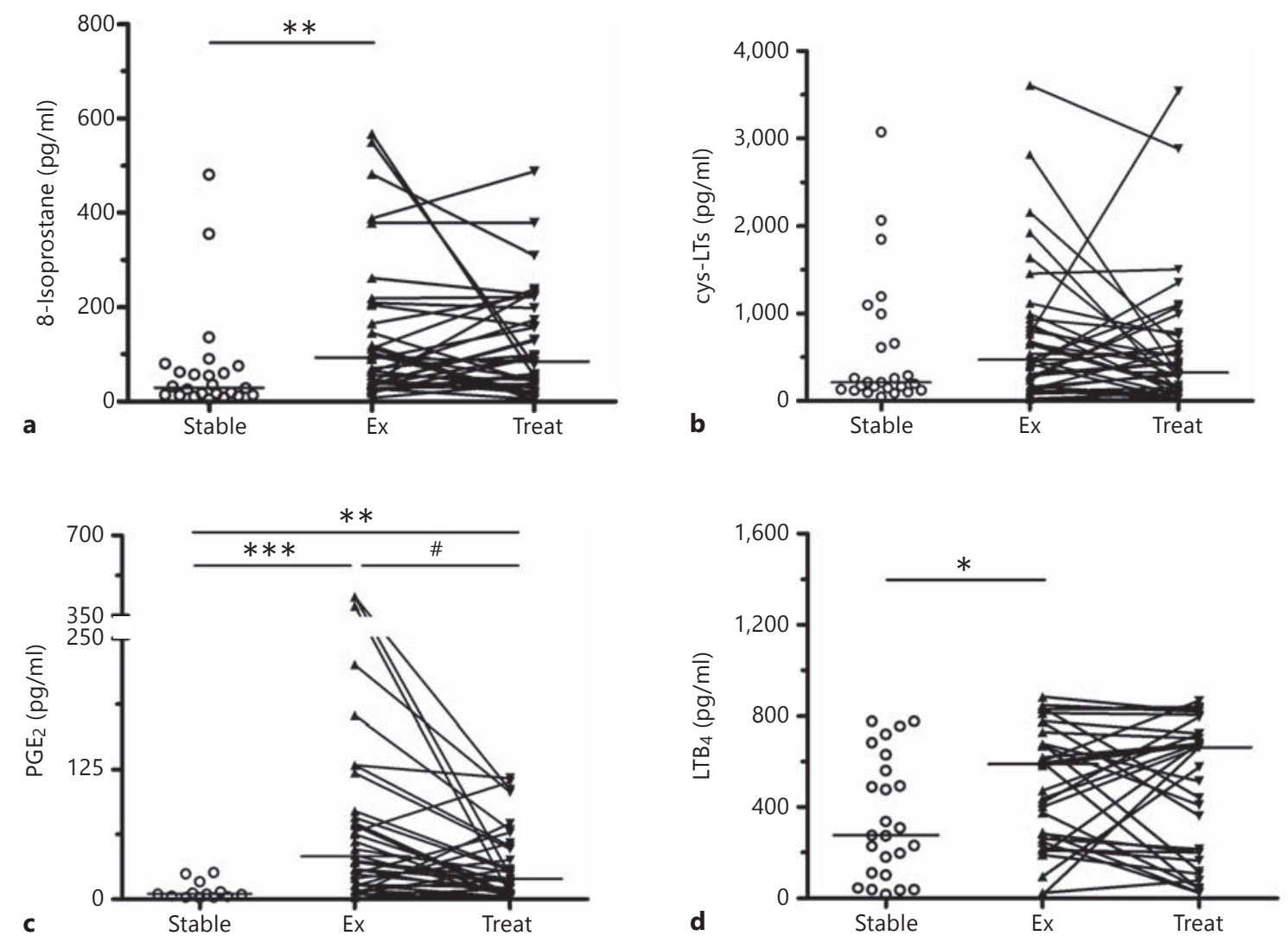

Fig. 2. Sputum 8-isoprostane (a), cys-LTs (b), $\mathrm{PGE}_{2}$ (c) and $\mathrm{LTB}_{4}$ (d) concentrations in stable COPD patients (Stable) and in COPD patients hospitalized at the time of an acute exacerbation (Ex) and after hospital treatment (Treat). In 3 patients with exacerbation

$\mathrm{LTB}_{4}$ and $\mathrm{PGE}_{2}$ levels were higher than the detection range of the kit. All patients were ex-smokers. Horizontal bars represent median values. ${ }^{*} \mathrm{p}<0.05,{ }^{* *} \mathrm{p}<0.01$ and ${ }^{* * *} \mathrm{p}<0.001$ vs. stable COPD patients, ${ }^{\#} \mathrm{p}<0.01$ vs. exacerbation.

Table 3. Correlations between sputum lipid mediator concentrations and clinical variables or sputum inflammatory cells in stable COPD patients and in those with exacerbations

\begin{tabular}{|c|c|c|c|c|c|c|c|c|}
\hline \multirow[t]{2}{*}{ Variables } & \multicolumn{2}{|c|}{8 -Isoprostane } & \multicolumn{2}{|c|}{ cys-LTs } & \multicolumn{2}{|l|}{$\mathrm{PGE}_{2}$} & \multicolumn{2}{|l|}{$\mathrm{LTB}_{4}$} \\
\hline & $\mathrm{r}$ value & $\mathrm{p}$ value & r value & $\mathrm{p}$ value & r value & $\mathrm{p}$ value & r value & $\mathrm{p}$ value \\
\hline $\mathrm{FEV}_{1}, \%$ predicted & -0.18 & 0.39 & -0.13 & 0.52 & -0.45 & 0.10 & 0.20 & 0.35 \\
\hline Neutrophils & 0.61 & $0.004^{\mathrm{a}}$ & 0.39 & 0.07 & 0.18 & 0.53 & 0.52 & $0.013^{\mathrm{a}}$ \\
\hline Lymphocytes & 0.64 & $0.002^{\mathrm{a}}$ & 0.60 & $0.003^{\mathrm{a}}$ & 0.27 & 0.35 & 0.38 & 0.084 \\
\hline $\mathrm{FEV}_{1}, \%$ predicted & 0.07 & 0.75 & -0.37 & 0.07 & 0.03 & 0.91 & -0.37 & 0.11 \\
\hline Neutrophils & -0.05 & 0.82 & 0.54 & $0.003^{\mathrm{a}}$ & 0.61 & $0.001^{\mathrm{a}}$ & 0.45 & $0.024^{\mathrm{a}}$ \\
\hline Lymphocytes & 0.07 & 0.72 & 0.55 & $0.002^{\mathrm{a}}$ & 0.69 & $<0.001^{\mathrm{a}}$ & 0.24 & 0.25 \\
\hline
\end{tabular}

a Significant correlations. 
$\mathrm{PGE}_{2}$ levels sharply increased at the onset of exacerbations compared to those in stable patients. Treatment of the condition resulted in a decrease in $\mathrm{PGE}_{2}$ concentrations. $\mathrm{LTB}_{4}$ and 8-isoprostane levels were also increased in exacerbations; however, levels remained elevated by the time of hospital discharge after treatment.

In contrast to $\mathrm{PGE}_{2}, \mathrm{LTB}_{4}$ or 8-isoprostane, sputum cys-LT concentrations were not elevated in COPD patients with exacerbations, indicating that cys-LTs may not significantly contribute to the development of airflow obstruction during exacerbations. Importantly, our study was sufficiently powered to detect a clinically meaningful change in cys-LT between a stable state and an exacerbation. Different mediator expressions could be present between eosinophilic and noneosinophilic airway inflammation [22]. Nonetheless, in our study, subgroup analysis based on the type of inflammation [eosinophilic (>2\%) vs. noneosinophilic $(<2 \%)$ ] revealed no change in cys-LTs either (data not shown).

Our finding that $\mathrm{PGE}_{2}$ concentrations in the sputum were increased in COPD exacerbations deserves comments. On the one hand, it is possible that this is merely a secondary protective regulatory response, as has been suggested in asthma [23] or COPD [7]. However, it is also conceivable that $\mathrm{PGE}_{2}$ is involved in neutrophilic recruitment into the airways, since there is evidence that $\mathrm{PGE}_{2}$ can enhance the adhesion of neutrophils to bronchial epithelial cells via a cyclooxygenase-2-dependent mechanism in COPD patients [8]. In line with this theory, $\mathrm{PGE}_{2}$ concentrations correlated with the number of neutrophils present in sputum samples at the time of exacerbation in our study. Interestingly, the number of lymphocytes showed an association with $\mathrm{PGE}_{2}$ levels as well. Finally, it is also possible that $\mathrm{PGE}_{2}$ influences airway inflammation and parenchymal destruction through the regulation of matrix metalloproteinases, since some studies suggest a relationship between the production of $\mathrm{PGE}_{2}$ and matrix metalloproteinase- 2 in the airways of COPD patients [24].

Although $\mathrm{PGE}_{2}$ concentrations decreased along with treatment of our patients, at discharge they were still markedly higher compared with those of stable COPD patients. It is possible that this was simply due to the high degree of neutrophilic airway inflammation present at this time point in our patients. Indeed, sputum neutrophil counts were elevated in patients at discharge compared to stable subjects and neutrophils represent a major source of $\mathrm{PGE}_{2}$ in the lung, as a result of induction by inflammatory cytokines such as TNF- $\alpha$ and IL- $1 \beta$, which activate NF- $\kappa \mathrm{B}$, the key regulator of cyclooxygenase- 2

Sputum Eicosanoid Profiling in COPD

Exacerbations
[25]. These inflammatory mediators might still be upregulated by the time of discharge and promote $\mathrm{PGE}_{2}$ synthesis in other cell types, for example, in fibroblasts as well [26]. Moreover, it has been reported that Moraxella catarrhalis and Haemophilus influenzae, which are major causes of infectious COPD exacerbations, can induce $\mathrm{PGE}_{2}$ release in pulmonary epithelial cells via a cyclooxygenase-2-dependent mechanism [27, 28]. It is possible that some of our patients were infected with these respiratory pathogens, which could persist even by the time of discharge. Nevertheless, sputum culture results were not specifically investigated in this study.

It is of note that in vivo $\mathrm{PGE}_{2}$ is rapidly converted to an inactive metabolite (13,14-dihydro-15-keto $\left.\mathrm{PGE}_{2}\right)$ by the PG 15-dehydrogenase pathway. Therefore, the determination of in vivo $\mathrm{PGE}_{2}$ biosynthesis is often best accomplished by the measurement of $\mathrm{PGE}_{2}$ metabolites. Thus, the EIA assay that was employed in our study first converts all major $\mathrm{PGE}_{2}$ metabolites into a single stable derivative which allows reliable estimate of in vivo $\mathrm{PGE}_{2}$ levels.

Our results about cys-LTs and $\mathrm{PGE}_{2}$ contrast with previous work assessing these eicosanoids in EBC [9]. We speculate that either the different nature of the specimens used (sputum vs. EBC) or the differences in the study cohort may explain the discrepancy between the results. In the study by Antczak et al. [9] only infectious exacerbations were investigated, while in our study positive sputum culture was not an inclusion criterion. The repeatability of sputum biomarker measurements such as 8-isoprostane and $\mathrm{LTB}_{4}$ in sputum is better than those reported by others for the same biomarkers in EBC [14].

Our finding that COPD patients with exacerbations have higher sputum $\mathrm{LTB}_{4}$ concentrations than stable subjects confirms the results of some previous studies $[3,4]$. Similarly, the significant correlation between sputum neutrophils and $\mathrm{LTB}_{4}$ levels is consistent with the general view that $\mathrm{LTB}_{4}$ is involved in neutrophil recruitment in COPD [29, 30] or asthma [31]. Interestingly, treatment had not resulted in a reduction of $\mathrm{LTB}_{4}$ concentrations. Nonetheless, delayed resolution of inflammatory response during recovery from exacerbation has been observed by other investigators as well [32]. Moreover, changes in sputum lipid mediator levels are not always directly related to anti-inflammatory treatment [33].

Earlier studies showed higher 8-isoprostane levels in the EBC and/or the sputum of stable COPD patients compared to healthy controls $[34,35]$. Here, we found that 8 -isoprostane levels were further elevated in COPD exacerbations. To the best of our knowledge, this has previ- 
ously been demonstrated only in EBC $[9,12,13]$. Our findings are in agreement with those of other trials showing increased oxidative stress in COPD patients with exacerbations using other markers such as exhaled hydrogen peroxide [36] or $\alpha_{1}$-antitrypsin [37]. However, sputum may be more suitable for assessing oxidative stress in respiratory diseases since the levels of potential markers including 8-isoprostane are 5- to 10-fold higher in the sputum than in the EBC [17]. Our data also indicate that a successful hospital treatment resulting in clinical and functional recovery of the patient does not abolish the increased oxidative stress observed in COPD exacerbations by the time of the patient's discharge from the hospital. Further studies with a longer follow-up period are needed to specifically investigate this issue.

In our study lung function parameters were not related to sputum lipid mediator levels. In other series investigating patients with asthma [38] or COPD exacerbations [9, 12] no such correlations were found either. Similarly, the association between lung function and sputum cytokine concentrations is often inconsistent [39].

We are aware that sputum induction, as opposed to spontaneous sputum collection, is the method of choice in patients with mild to moderate COPD [40]. However, as a large percentage ( $50 \%)$ of our recruits had severe or very severe COPD, spontaneous sputum collection, rather than sputum induction was chosen in patients with exacerbation because of safety concerns. Since the induc- tion by itself had no effect on eicosanoid readings, direct comparison of the induced and spontaneous sputum specimens was feasible.

Several lines of evidence indicate that cigarette smoking is a confounding factor in eicosanoid measurements $[8$, $34,41]$. Since our recruitment strategy called for only exsmokers, smoking status had no influence on our results.

In conclusion, we found elevated $\mathrm{PGE}_{2}$ concentrations in the sputum in relation with increased airway inflammation in patients with COPD exacerbations. $\mathrm{PGE}_{2}$ decreased along with clinical recovery. During exacerbations sputum 8-isoprostane levels were also elevated indicating augmented oxidative stress. Finally, while increased $\mathrm{LTB}_{4}$ could contribute to enhanced neutrophilic influx during exacerbations, no evidence for a major role of cys-LTs in exacerbations was found. The utility of $\mathrm{PGE}_{2}$ measurements in the sputum should be investigated further to clarify its possible role as a marker of recovery from a COPD exacerbation.

\section{Acknowledgments}

We thank M. Mikoss and J. Hernadi (National Koranyi Institute of TB and Pulmonology) for their assistance in sputum collection and processing. The study was supported by the Hungarian Respiratory Foundation and by the Hungarian National Scientific Foundation (OTKA K83338). Dr. B. Antus is a recipient of Bolyai Janos Scholarship of the Hungarian Academy of Sciences.

\section{References}

1 Bathoorn E, Kerstjens H, Postma D, Timens W, MacNee W: Airways inflammation and treatment during acute exacerbations of COPD. Int J Chron Obstruct Pulmon Dis 2008;3:217-229.

- 2 Lundström SL, Balgoma D, Wheelock ÅM, Haeggström JZ, Dahlén SE, Wheelock CE: Lipid mediator profiling in pulmonary disease. Curr Pharm Biotechnol 2011;12:10261052.

-3 Bathoorn E, Liesker JJ, Postma DS, Koëter $\mathrm{GH}$, van der Toorn M, van der Heide S, Ross HA, van Oosterhout AJ, Kerstjens HA: Change in inflammation in out-patient COPD patients from stable phase to a subsequent exacerbation. Int J Chron Obstruct Pulmon Dis 2009;4:101-109.

-4 Crooks SW, Bayley DL, Hill SL, Stockley RA: Bronchial inflammation in acute bacterial exacerbations of chronic bronchitis: the role of leukotriene B4. Eur Respir J 2000;15:274-280.

5 Laidlaw TM, Boyce JA: Cysteinyl leukotriene receptors, old and new; implications for asthma. Clin Exp Allergy 2012;42:1313-1320.
6 Pavord ID, Tattersfield AE: Bronchoprotective role for endogenous prostaglandin E2. Lancet 1995;345:436-438.

7 Montuschi P, Kharitonov SA, Ciabattoni G, Barnes PJ: Exhaled leukotrienes and prostaglandins in COPD. Thorax 2003;58:585-588.

-8 Profita M, Sala A, Bonanno A, Riccobono L, Ferraro M, La Grutta S, Albano GD, Montalbano AM, Gjomarkaj M: Chronic obstructive pulmonary disease and neutrophil infiltration: role of cigarette smoke and cyclooxygenase products. Am J Physiol Lung Cell Mol Physiol 2010;298:261-269.

-9 Antczak A, Ciebiada M, Pietras T, Piotrowski WJ, Kurmanowska Z, Górski P: Exhaled eicosanoids and biomarkers of oxidative stress in exacerbation of chronic obstructive pulmonary disease. Arch Med Sci 2012;8:277-285.

10 Zhu J, Bandi V, Qiu S, Figueroa DJ, Evans JF, Barnes N, Guntupalli KK, Jeffery PK: Cysteinyl leukotriene 1 receptor expression associated with bronchial inflammation in severe exacerbations of COPD. Chest 2012;142:347357.
11 Wood LG, Gibson PG, Garg ML: Biomarkers of lipid peroxidation, airway inflammation and asthma. Eur Respir J 2003;21:177-186.

12 Biernacki WA, Kharitonov SA, Barnes PJ: Increased leukotriene B4 and 8-isoprostane in exhaled breath condensate of patients with exacerbations of COPD. Thorax 2003; 58: 294-298.

13 Carpagnano GE, Resta O, Foschino-Barbaro MP, Spanevello A, Stefano A, Di Gioia G, Serviddio G, Gramiccioni E: Exhaled interleukine-6 and 8-isoprostane in chronic obstructive pulmonary disease: effect of carbocysteine lysine salt monohydrate (SCMC-Lys). Eur J Pharmacol 2004;505:169-175.

14 Borrill ZL, Starkey RC, Singh SD: Variability of exhaled breath condensate leukotriene $\mathrm{B} 4$ and 8-isoprostane in COPD patients. Int J Chron Obstruct Pulmon Dis 2007;2: 71-76.

15 Franklin P, Moeller A, Hall GL, Horak F Jr, Patterson H, Stick SM: Variability of nitric oxide metabolites in exhaled breath condensate. Respir Med 2006;100:123-129. 
16 Horváth I, Hunt J, Barnes PJ, Alving K, Antczak A, Baraldi E, Becher G, van Beurden WJ, Corradi M, Dekhuijzen R, Dweik RA, Dwyer T, Effros R, Erzurum S, Gaston B, Gessner C, Greening A, Ho LP, Hohlfeld J, Jöbsis Q, Laskowski D, Loukides S, Marlin D, Montuschi $\mathrm{P}$, Olin AC, Redington AE, Reinhold $\mathrm{P}$, van Rensen EL, Rubinstein I, Silkoff P, Toren K, Vass G, Vogelberg C, Wirtz H: ATS/ERS Task Force on Exhaled Breath Condensate. Exhaled breath condensate: methodological recommendations and unresolved questions. Eur Respir J 2005;26:523-548.

-17 Mazur W, Stark H, Sovijärvi A, Myllärniemi M, Kinnula VL: Comparison of 8-isoprostane and interleukin- 8 in induced sputum and exhaled breath condensate from asymptomatic and symptomatic smokers. Respiration 2009; 78:209-216.

18 Rabe KF, Hurd S, Anzueto A, et al: Global strategy for the diagnosis, management, and prevention of chronic obstructive pulmonary disease: GOLD Executive Summary. Am J Respir Crit Care Med 2007;176:532-555.

19 Antus B, Barta I, Kullmann T, Lazar Z, Valyon M, Horvath I, Csiszer E: Assessment of exhaled breath condensate $\mathrm{pH}$ in exacerbations of asthma and chronic obstructive pulmonary disease: a longitudinal study. Am J Respir Crit Care Med 2010;182:1492-1497.

20 Antus B, Barta I, Csiszer E, Kelemen K: Exhaled breath condensate $\mathrm{pH}$ in patients with cystic fibrosis. Inflamm Res 2012;61:11411147.

-21 Gaber F, Acevedo F, Delin I, Sundblad BM, Palmberg L, Larsson K, Kumlin M, Dahlén SE: Saliva is one likely source of leukotriene B4 in exhaled breath condensate. Eur Respir J 2006;28:1229-1235.

22 Bafadhel M, McCormick M, Saha S, McKenna S, Shelley M, Hargadon B, Mistry V, Reid C, Parker D, Dodson P, Jenkins M, Lloyd A, Rugman P, Newbold P, Brightling CE: Profiling of sputum inflammatory mediators in asthma and chronic obstructive pulmonary disease. Respiration 2012;83:36-44.

23 Aggarwal S, Moodley YP, Thompson PJ, Misso NL: Prostaglandin E2 and cysteinyl leukotriene concentrations in sputum: association with asthma severity and eosinophilic inflammation. Clin Exp Allergy 2010;40:85-93.
24 Chen Y, Chen P, Hanaoka M, Droma Y, Kubo $\mathrm{K}$ : Enhanced levels of prostaglandin E2 and matrix metalloproteinase- 2 correlate with the severity of airflow limitation in stable COPD. Respirology 2008;13:1014-1021.

25 Newton R, Kuitert LM, Bergmann M, Adcock IM, Barnes PJ: Evidence for involvement of NF-kappaB in the transcriptional control of COX-2 gene expression by IL-1beta. Biochem Biophys Res Commun 1997;237:28-32.

26 Sato T, Liu X, Nelson A, Nakanishi M, Kanaji N, Wang X, Kim M, Li Y, Sun J, Michalski J, Patil A, Basma H, Holz O, Magnussen $\mathrm{H}$, Rennard SI: Reduced miR-146a increases prostaglandin $\mathrm{E}_{2}$ in chronic obstructive pulmonary disease fibroblasts. Am J Respir Crit Care Med 2010;182:1020-1029.

27 Xu F, Xu Z, Zhang R, Wu Z, Lim JH, Koga T, Li JD, Shen H: Nontypeable Haemophilus influenzae induces COX-2 and PGE2 expression in lung epithelial cells via activation of p38 MAPK and NF-kappa B. Respir Res 2008; 9:16.

-28 N'Guessan PD, Temmesfeld-Wollbrück B, Zahlten J, Eitel J, Zabel S, Schmeck B, Opitz B, Hippenstiel S, Suttorp N, Slevogt H: Moraxella catarrhalis induces ERK- and NF-kappaB-dependent COX-2 and prostaglandin E2 in lung epithelium. Eur Respir J 2007;30:443451.

29 Corhay JL, Henket M, Nguyen D, Duysinx B, Sele J, Louis R: Leukotriene B4 contributes to exhaled breath condensate and sputum neutrophil chemotaxis in COPD. Chest 2009;136: 1047-1054.

30 Warwick G, Thomas PS, Yates DH: Non-invasive biomarkers in exacerbation of obstructive lung disease. Respirology 2013;18:874884.

31 Pelikan Z: Delayed asthmatic response to bronchial challenge with allergen-mediators, eicosanoids, eosinophil and neutrophil constituents in the blood and urine. Respiration 2011;82:225-236.

32 Mohan A, Prasad D, Sharma A, Arora S, Guleria R, Sharma SK, Pandey RM: Delayed resolution of inflammatory response compared with clinical recovery in patients with acute exacerbations of chronic obstructive pulmonary disease. Respirology 2012;17: 1080-1085.
33 Takemura M, Niimi A, Matsumoto H, Ueda $T$, Matsuoka $H$, Yamaguchi $M$, Jinnai $M$, Chin K, Mishima M: Clinical, physiological and anti-inflammatory effect of montelukast in patients with cough variant asthma. Respiration 2012;83:308-315.

34 Montuschi P, Collins JV, Ciabattoni G, Lazzeri N, Corradi M, Kharitonov SA, Barnes PJ: Exhaled 8-isoprostane as an in vivo biomarker of lung oxidative stress in patients with COPD and healthy smokers. Am J Respir Crit Care Med 2000;162:1175-1177.

35 Kinnula VL, Ilumets H, Myllärniemi M, Sovijärvi A, Rytilä P: 8-Isoprostane as a marker of oxidative stress in nonsymptomatic cigarette smokers and COPD. Eur Respir J 2007;29:5155.

36 Dekhuijzen PN, Aben KK, Dekker I, Aarts LP, Wielders PL, van Herwaarden CL, Bast A: Increased exhalation of hydrogen peroxide in patients with stable and unstable chronic obstructive pulmonary disease. Am J Respir Crit Care Med 1996;154:813-816.

37 Koczulla AR, Noeske S, Herr C, Koepke J, Jörres RA, Nell C, Schmid S, Vogelmeier C, Bals R: Alpha- 1 antitrypsin is elevated in exhaled breath condensate and serum in exacerbated COPD patients. Respir Med 2012;106: 120-126.

38 Baraldi E, Carraro S, Alinovi R, Pesci A, Ghiro L, Bodini A, Piacentini G, Zacchello F, Zanconato S: Cysteinyl leukotrienes and 8-isoprostane in exhaled breath condensate of children with asthma exacerbations. Thorax 2003;58:505-509.

39 Grubek-Jaworska H, Paplińska M, Hermanowicz-Salamon J, Białek-Gosk K, Dąbrowska M, Grabczak E, Domagała-Kulawik J, Stępień J, Chazan R: IL-6 and IL-13 in induced sputum of COPD and asthma patients: correlation with respiratory tests. Respiration 2012; 84:101-107.

40 Bathoorn E, Liesker J, Postma D, Koëter G, van Oosterhout AJ, Kerstjens HA: Safety of sputum induction during exacerbations of COPD. Chest 2007;131:432-438.

41 Carpagnano GE, Kharitonov SA, FoschinoBarbaro MP, Resta O, Gramiccioni E, Barnes PJ: Increased inflammatory markers in the exhaled breath condensate of cigarette smokers. Eur Respir J 2003;21:589-593. 